\title{
Kamera mit Handyfunktion
}

Dass Smartphones Kameras haben, ist inzwischen zum Standard geworden. Mit „richtigen“ Fotoapparaten können diese in der Regel allerdings nicht mithalten. Aufhorchen ließ Nokia bereits mit der Kamerafunktion im Lumia 920, die, gerade bei schwierigen Lichtverhältnissen, Beeindruckendes leistet. Mit dem neuen Lumia 1020 macht es Nokia noch besser. Die integrierte Kamera dieses Smartphones verfügt nicht nur über einen optischen Bildstabilisator und ein Carl-Zeiss-Objektiv, sondern über eine Auflösung von 41 Megapixeln.

Der Sinn des 41-Megapixel-Sensors besteht allerdings nicht darin, tatsächlich mit derart hoher Auflösung zu fotografieren. Vielmehr soll durch sogenanntes „Oversampling“ eine bessere Bildqualität erreicht werden. Das Lumia 1020 verbindet so eine herausragende Bildqualität mit der Möglichkeit, Schnappschüsse sofort etwa bei Facebook zu veröffentlichen. Es heißt dann nicht mehr Konnektivität oder gute Bildqualität, sondern beides.
Wie auf allen aktuellen Nokia Smartphones läuft auch auf dem Lumia 1020 Windows Phone 8 als Betriebssystem. MS Office gehört deshalb zur Grundausstattung. Microsoft war mit seinem Smartphone-Betriebssystem zwar der Spätstarter, hat aber die Zeit genutzt, um ein rundum stimmiges System zu bauen, dass im mobilen Alltag bestens funktioniert. Zwar gibt es (noch) deutlich weniger Apps als für iOS oder Android, aber nahezu alle beliebten und wirklich nützlichen sind auch für dieses Betriebssystem erhältlich.

Nokia legt, wie bereits seit einigen Jahren, außerdem eine kostenlose sprachgeführte Navigationssoftware obendrauf, die nicht auf eine Internetverbindung angewiesen ist - wichtig etwa im Ausland. Wer möchte, kann mit diesem Handy daher Kompaktkamera und Navi ersetzen, ohne Einbußen bei der Qualität befürchten zu müssen.

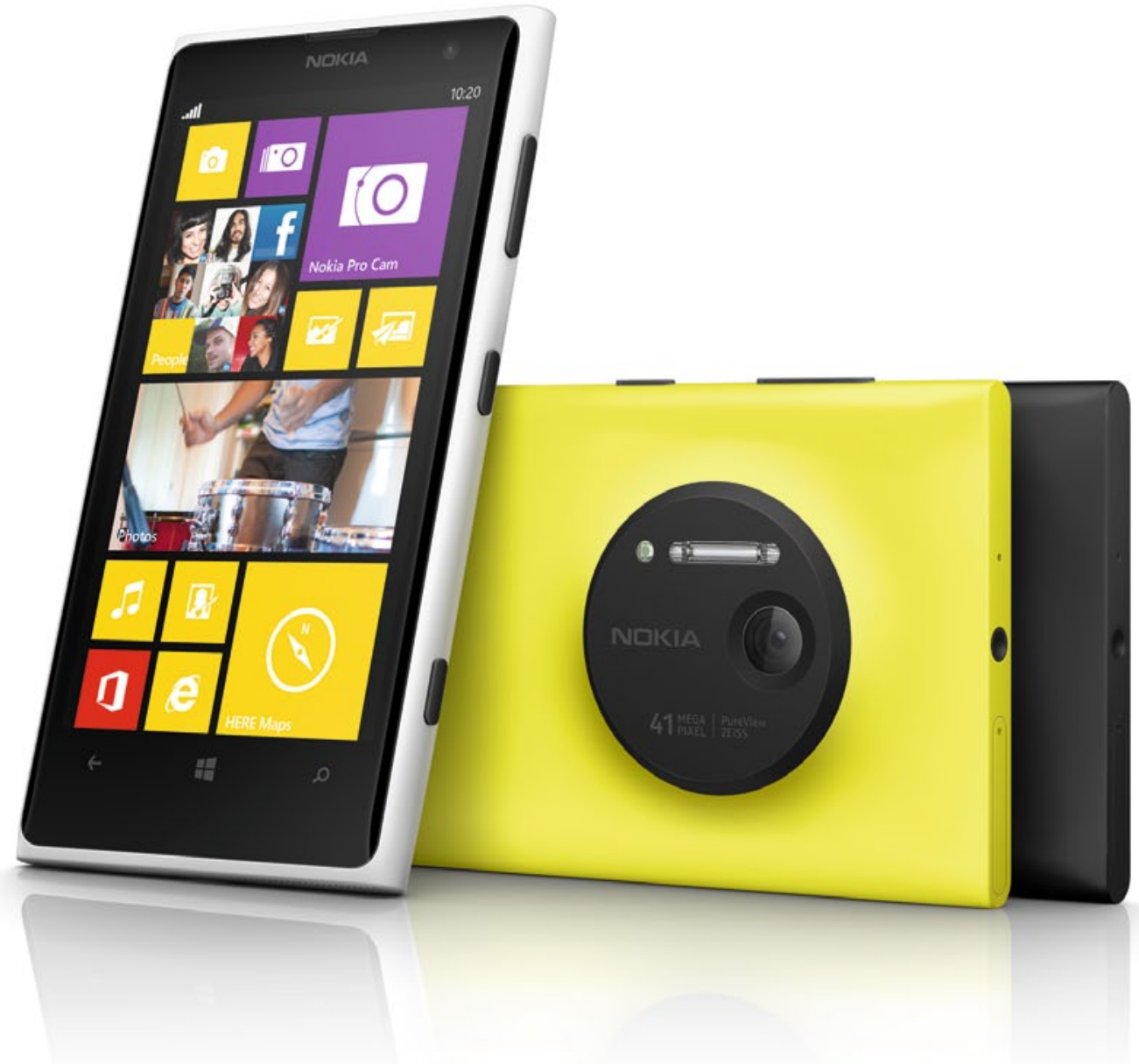

Herausragende Kamera das Lumia 1020. 